\title{
Effect of Anion Doping on Mobility of Ionic Charge Carriers in Solid Solutions Based on $\mathrm{Ba}_{2} \mathrm{In}_{2} \mathrm{O}_{5}$
}

\author{
N. A. Tarasova ${ }^{z}$ and I. E. Animitsa \\ Ural Federal University Named after the First President of Russia B.N. Eltsin, ul. Mira 19, 620002 Ekaterinburg, Russia \\ Received June 29, 2012
}

\begin{abstract}
In the work, mobilities of oxygen and protons are determined for $\mathrm{F}^{-}$-substituted solid solutions based on brownmillerite $\mathrm{Ba}_{2} \mathrm{In}_{2} \mathrm{O}_{5}$ and their concentration dependences are analyzed. It is found that small additives of the more mobile anion ( $\mathrm{F}^{-}$ions) promote an increase in oxygen mobility as a result of additional effects of repulsion of ions of different nature in the anion sublattice. Mobility of oxygen at high fluoride concentrations decreases due to the overlapping of migration paths of diffusion, as both anions, fluoride ions and oxygen ions, move via oxygen vacancies. Concentration dependences of mobility of proton carriers have a similar character, which is related to the effect of the oxygen sublattice. The anion doping method used in the work can be recommended as the general method for improvement of the transport characteristics of oxygen-ionic and protonic conductors with a perovskite-like structure.
\end{abstract}

Keywords: brownmillerite, oxyfluoride, anion doping, ion conductivity, oxygen mobility, proton mobility

DOI: $10.1134 / \mathrm{S} 1023193513070161$

\section{INTRODUCTION}

One of the topical problems of chemical materials science is the search for new ceramic materials with the given properties for application in different electrochemical devices. Among these, a special place is occupied by proton electrolytes, as proton as a charge carrier can manifest high mobility due to its specific properties and thus provides a significant level of transport characteristics. Owing to selective transport of protons, many protonic solid electrolytes have already found practical application as membranes of such devices as fuel cells, hydrogen pumps and sensors, electrolyzers for hydrogen production, membrane reactors for hydrocarbon (de)hydration [1].

Promising phases among complex oxide compounds with proton conductivity are phases with a perovskite structure or a structure derived from such. The presence of vacant positions in an anion sublattice promotes the possibility of dissociative absorption of water vapors and appearance of proton conductivity. Oxygen vacancies can be formed via acceptor doping or appear as a structural defect. The maximum oxygen deficiency is characteristic for phases with the structure of brownmillerite $\mathrm{A}_{2} \mathrm{~B}_{2} \mathrm{O}_{5}$ and $\mathrm{A}_{2} \mathrm{BB}^{\prime} \mathrm{O}_{5}$ that can reversibly absorb up to $1 \mathrm{~mol}$ of water per formula unit. Barium indate $\mathrm{Ba}_{2} \mathrm{In}_{2} \mathrm{O}_{5}$ is best studied as regards transport characteristics. Optimization of its properties is reached using various substitutions. At present, the doping of cation A and B sublattices is best studied [2-20]. However, implementation of the method of

\footnotetext{
${ }^{z}$ Corresponding author: Natalia.Tarasova@usu.ru (N.A. Tarasova).
}

anion substitution can open fundamentally new ways for modification of the structure and transport properties of compounds. One could assume that introduction of ions of different nature into the anion sublattice largely affects oxygen mobility and therefore of protons, as dynamics of the oxygen sublattice determines their mobility.

We showed in our previous works [21-24] the fundamental possibility of obtaining new oxyfluoride phases based on barium indate $\mathrm{Ba}_{2} \mathrm{In}_{2} \mathrm{O}_{5}$ by partial substitution of oxygen ions by fluoride ions $\left(\mathrm{F}^{-} \rightarrow \mathrm{O}^{2-}\right)$. Variation of the $\mathrm{BaO} / \mathrm{BaF}_{2}$ ratio leads, on the one hand, to formation of solid solutions without any variation in the amount of oxygen vacancies, but with formation of vacancies in the cation sublattice of barium according to the formula of $\mathrm{Ba}_{2-0.5 x}\left[\mathrm{~V}_{\mathrm{Ba}}\right]_{0.5 x} \mathrm{In}_{2} \mathrm{O}_{5-x} \mathrm{~F}_{x}\left[\mathrm{~V}_{\mathrm{o}}\right]_{1}$ and on the other hand, to a decrease in the amount of anion vacancies according to the formula of $\mathrm{Ba}_{2} \mathrm{In}_{2} \mathrm{O}_{5-0.5 y} \mathrm{~F}_{y}\left[\mathrm{~V}_{\mathrm{o}}\right]_{1-0.5 y}$.

The results of electric measurements in the solid solutions of $\mathrm{Ba}_{2-0.5 x} \operatorname{In}_{2} \mathrm{O}_{5-x} \mathrm{~F}_{x}(0 \leq x \leq 0.30)$ and $\mathrm{Ba}_{2} \mathrm{In}_{2} \mathrm{O}_{5-0.5 y} \mathrm{~F}_{y}(0 \leq y \leq 0.24)$ showed that introduction of small concentrations of fluoride into the structure of complex oxides resulted in a drastic increase in conductivity. Elucidation of the mature of this effect requires analyzing mobility of ionic charge carriers.

The aim of the present work was to establish the effect of anion doping of $\mathrm{F}^{-} \rightarrow \mathrm{O}^{2-}$ on the mobility of oxygen and protons in solid solutions based on $\mathrm{Ba}_{2} \mathrm{In}_{2} \mathrm{O}_{5}$. 


\section{EXPERIMENTAL}

Samples of $\mathrm{Ba}_{2-0.5 x} \mathrm{In}_{2} \mathrm{O}_{5-x} \mathrm{~F}_{x}(0 \leq x \leq 0.30)$ and $\mathrm{Ba}_{2} \mathrm{In}_{2} \mathrm{O}_{5-0.5 y} \mathrm{~F}_{y}(0 \leq y \leq 0.24)$ were obtained using the solid state synthesis technique from predehydrated $\mathrm{BaCO}_{3}, \mathrm{In}_{2} \mathrm{O}_{3}, \mathrm{BaF}_{2}$. Synthesis was carried out in air under a stepwise temperature increase $\left(800-1200^{\circ} \mathrm{C}\right)$ and repeated grinding.

$\mathrm{X}$-ray analysis was carried out using a Bruker D8 Advance diffractometer in $\mathrm{Cu} K_{\alpha}$ radiation in the angle range of $2 \theta=10^{\circ}-80^{\circ}$. Lattice parameters were calculated using the Celref software.

Thermal analysis of hydrated samples was carried out at a TG STA 409 PC Luxx NETZSCH thermal analyzer in the temperature range of $25-1300^{\circ} \mathrm{C}$; the heating rate was $10^{\circ} \mathrm{C} / \mathrm{min}$.

In order to measure electric properties, samples were prepared in the form of tablets; the sintering was carried out at the temperature of $1300^{\circ} \mathrm{C}$ for $24 \mathrm{~h}$. The density of the obtained ceramics was $\sim 85 \%$. The burning-in of platinum electrodes was carried out at the temperature of $900^{\circ} \mathrm{C}$ for $3 \mathrm{~h}$.

Conductivity was studied using the electrochemical impedance technique in the frequency range of $1 \mathrm{~Hz}$ to $1 \mathrm{MHz}$ with the signal amplitude of $15 \mathrm{mV}$ using the IPI-3 meter of impedance parameters. All electrochemical measurements were carried out under the conditions of equilibrium with $T, p \mathrm{H}_{2} \mathrm{O}$, and $p \mathrm{O}_{2}$. Bulk resistance was calculated using the Zview software. Specific conductivity was calculated according to the following equation:

$$
\sigma_{\mathrm{sp}}=\frac{1}{R}\left(\frac{l}{S}\right)
$$

where $l$ is the sample thickness, $\mathrm{cm}$; $S$ is the cross-section surface area, $\mathrm{cm}^{2} ; R$ is the sample bulk resistance, $\mathrm{Ohm}$, calculated on the basis of the electrochemical impedance data.

Conductivity of the studied phases was measured in atmospheres with different humidity and $p \mathrm{O}_{2}$. A humid atmosphere was obtained by air bubbling at the room temperature successively through distilled water and saturated potassium bromide $\mathrm{KBr}$ solution $\left(p \mathrm{H}_{2} \mathrm{O}=1.92 \times 10^{-2} \mathrm{~atm}\right)$. Dry atmosphere was provided by gas circulation through powdered phosphorus pentoxide $\mathrm{P}_{2} \mathrm{O}_{5}\left(p \mathrm{H}_{2} \mathrm{O}=3.2 \times 10^{-5} \mathrm{~atm}\right)$. Besides, preliminary removal of carbon dioxide $\mathrm{CO}_{2}$ from air was carried out to prevent the possible carbonization of ceramics: using a $20 \% \mathrm{NaOH}$ solution for a humid atmosphere, using the Askarite reagent for a dry atmosphere. Gas humidity was controlled using an IVG-1 MK-S meter of gas humidity.

Conductivity under $p \mathrm{O}_{2}$ variation was studied in the range of partial oxygen pressures of 0.21 to $10^{-20} \mathrm{~atm}$. Oxygen pressure was set and controlled using an "oxygen pump" and oxygen partial pressure sensor made of stabilized solid electrolyte based on $\mathrm{ZrO}_{2}$.

The methods of separating total conductivity to partial contributions are presented in [24].

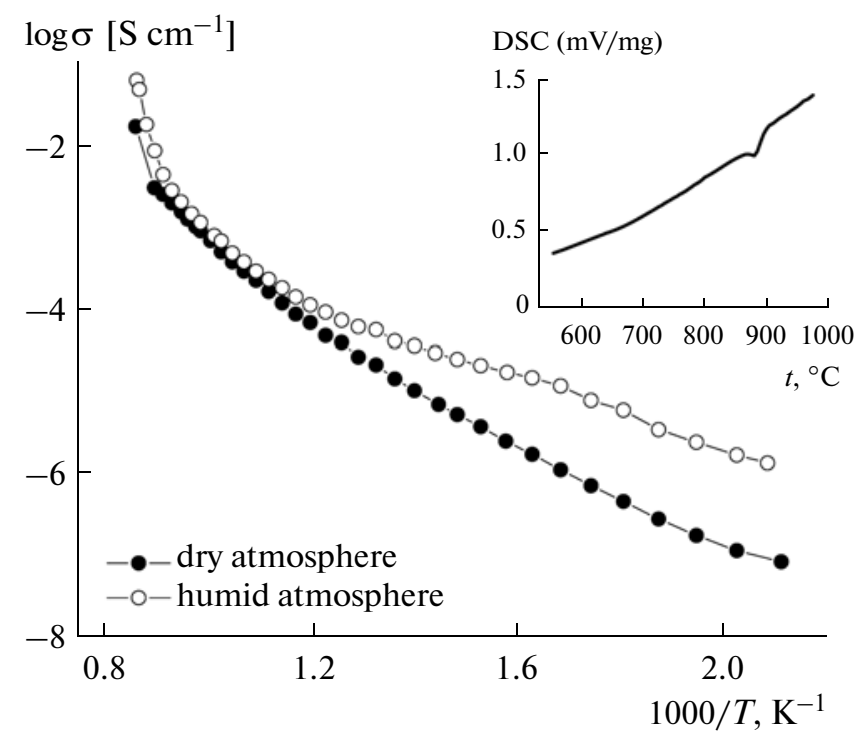

Fig. 1. Temperature dependences of total conductivity of $\mathrm{Ba}_{1.95} \mathrm{In}_{2} \mathrm{O}_{4.9} \mathrm{~F}_{0.10}$ in a dry $\left(\mathrm{HH}_{2} \mathrm{O}=3.2 \times 10^{-5}\right.$ atm $)$ and humid $\left(p \mathrm{H}_{2} \mathrm{O}=1.92 \times 10^{-2} \mathrm{~atm}\right)$ atmosphere; the inset shows the DSC curve.

\section{RESULTS AND DISCUSSION}

Earlier, we found that the $\mathrm{Ba}_{2} \mathrm{In}_{2} \mathrm{O}_{5-0.5 y} \mathrm{~F}_{y}, 0 \leq y \leq 0.24$ solid solution based on barium indate $\mathrm{Ba}_{2} \mathrm{In}_{2} \mathrm{O}_{5}$ was formed [23, 24]. However, a homogeneity region adjacent to the composition of $\mathrm{Ba}_{2} \mathrm{In}_{2} \mathrm{O}_{5}$ obviously exists in the system of $\mathrm{BaO}-\mathrm{BaF}_{2}-\mathrm{In}_{2} \mathrm{O}_{3}$. Accordingly, solid solutions can be formed for different quasibinary sections. We obtained solid solutions of $\mathrm{Ba}_{2-0.5 x} \mathrm{In}_{2} \mathrm{O}_{5-x} \mathrm{~F}_{x}$ in the range of $0 \leq x \leq 0.30$ that were also characterized by a brownmillerite structure with a body-centered orthorhombic lattice, space group Ibm2 (for $\mathrm{Ba}_{2} \mathrm{In}_{2} \mathrm{O}_{5}$ $a=0.6094(1) \mathrm{nm}, b=1.6740(2) \mathrm{nm}, c=0.5959(3) \mathrm{nm}$, $\alpha=\beta=\gamma=90^{\circ}$ ); introduction of $\mathrm{F}^{-}$also resulted in no significant changes in the lattice parameters.

Figures 1, 2 show typical dependences of total conductivity at a change in the temperature and $p \mathrm{O}_{2}$ for a dry and humid atmosphere for some compositions in the homogeneity range of $\mathrm{Ba}_{2-0.5 x} \mathrm{In}_{2} \mathrm{O}_{5-x} \mathrm{~F}_{x}$.

For the studied solid solution of $\mathrm{Ba}_{2-0.5 x} \mathrm{In}_{2} \mathrm{O}_{5-x} \mathrm{~F}_{x}$, all the main regularities regarding transport properties described for the solid solution of $\mathrm{Ba}_{2} \mathrm{In}_{2} \mathrm{O}_{5-0.5 y} \mathrm{~F}_{y}$ were preserved [24]. Generalizing these data allows stating the main aspects. For temperature dependences of conductivity (Fig. 1): sensitivity of conductivity to the presence of water vapor is registered below $600^{\circ} \mathrm{C}$, which points to appearance of the proton contribution of conductivity; the phase "order-disorder" transition characteristic for $\mathrm{Ba}_{2} \mathrm{In}_{2} \mathrm{O}_{5}$ is preserved for all compositions in the temperature range of $\sim 900^{\circ} \mathrm{C}$. It is accompanied by the endothermal effect on the curve obtained using the method of differential scanning calorimetry (DSC) (Fig. 1, the inset). For isotherms of $\sigma-f\left(p \mathrm{O}_{2}\right)$ (Fig. 2): the dependences have a positive slope in the range of high partial pressures of 


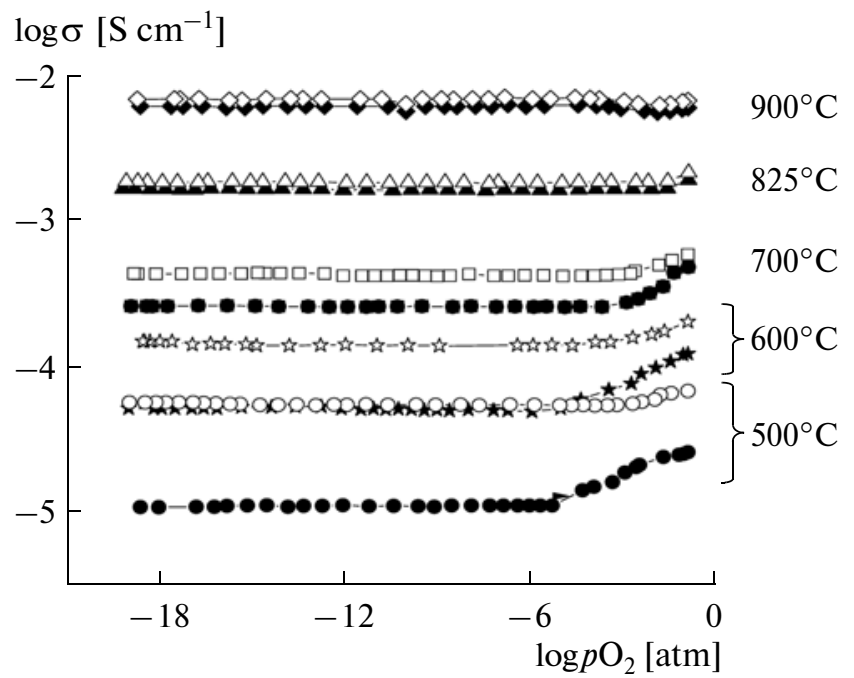

Fig. 2. Dependence of total conductivity on the partial pressure of oxygen for the composition of $\mathrm{Ba}_{1.975} \mathrm{In}_{2} \mathrm{O}_{4.95} \mathrm{~F}_{0.05}(x=0.05)$ in a dry (filled symbols) and a humid (open symbols) atmosphere.

oxygen, which points to appearance of the contribution of $p$-type electron conductivity. In the range of medium and low values of $p \mathrm{O}_{2}$, conductivity does not depend on the pressure of oxygen, which points to the predominant contribution of ion conductivity. An increase in total conductivity is observed in the whole range of $p \mathrm{O}_{2}$ in a humid atmosphere (at the temperature below $700^{\circ} \mathrm{C}$ ) as compared to a dry one, which is related to an increase in the concentration of proton defects and appearance of proton contribution in conductivity. Having performed a complex of measurements to separate total conductivity into partial contributions [24], we focused our attention in this work on analysis of concentration dependences of conductivities.

It is found for both solid solutions that introduction of low concentrations of fluoride into the structure of complex oxides results in a drastic increase in conductivity. Figures 3, 4 show concentration dependences of total and partial conductivity for the solid solutions of $\mathrm{Ba}_{2-0.5 x} \operatorname{In}_{2} \mathrm{O}_{5-x} \mathrm{~F}_{x}$ and $\mathrm{Ba}_{2} \operatorname{In}_{2} \mathrm{O}_{5-0.5 y} \mathrm{~F}_{y}$ in a dry and humid atmosphere. One can see that irrespective of the mechanism of introduction of fluoride, the general trend of an increase in conductivity at low dopant concentrations is observed for all the studied compositions. The presence of the maximum of ionic conductivity of solid solutions with two types of mobile anions was determined as the polyanion effect [22] (by analogy with the known effect for cation conductors with the opposite trend). Analysis of mobilities of ionic current carriers is required to elucidate the factors determining this dependence. The calculations below are made under the assumption that all ions participate in electric transport. In other words, these values are esti-
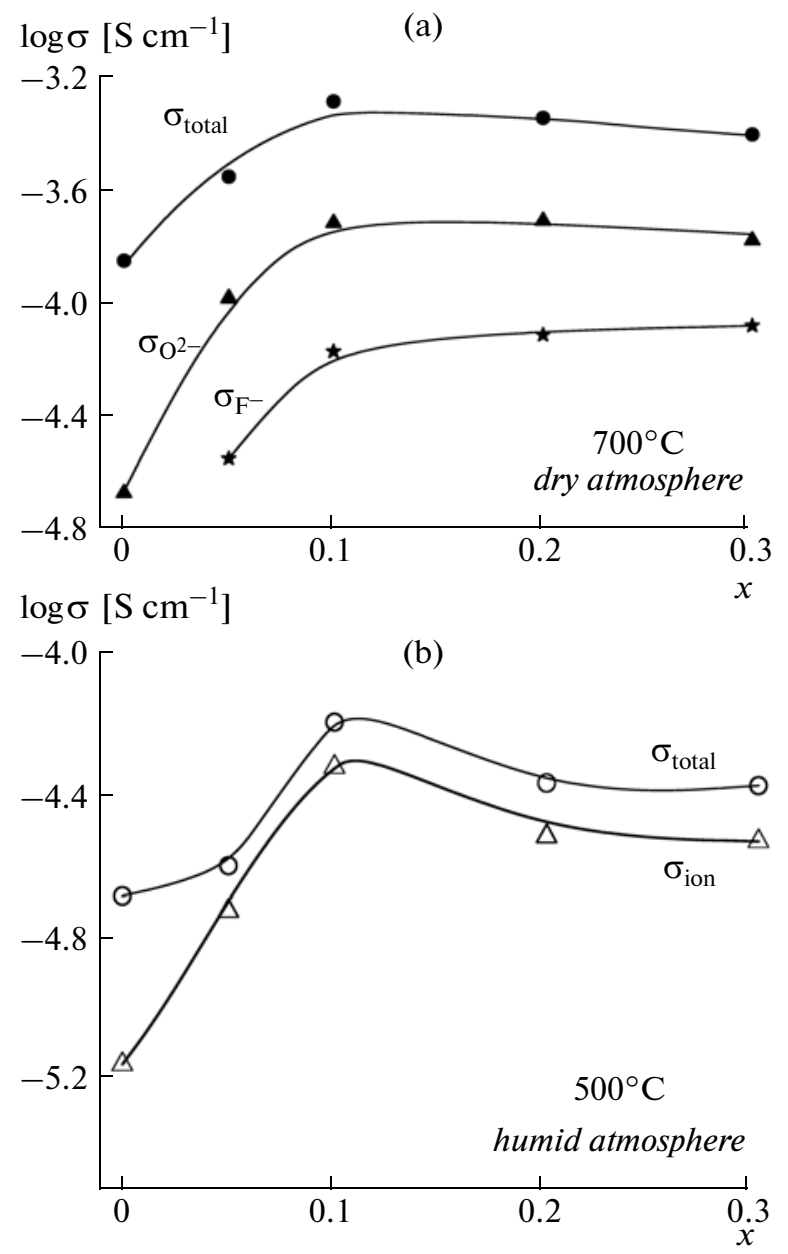

Fig. 3. Concentration dependences of total and partial conductivity for solid solutions of $\mathrm{Ba}_{2}-0.5 x \mathrm{In}_{2} \mathrm{O}_{5-x} \mathrm{~F}_{x}$ in (a) a dry atmosphere at $700^{\circ} \mathrm{C}$ and (b) a humid atmosphere at $500^{\circ} \mathrm{C}$.

mates, but nevertheless, they allow tracing the main regularities of ion transport.

Mobility of oxygen vacancies can be calculated on the basis of the known relationship:

$$
\sigma_{\mathrm{v}_{\mathrm{o}}^{\mathrm{x}}}=Z e c_{\mathrm{v}_{\mathrm{o}}^{\mathrm{x}}} \mu_{\mathrm{v}_{\mathrm{o}}^{\mathrm{x}}},
$$

where $Z e$ is the absolute charge value; $c_{\mathrm{v}_{\mathrm{o}}^{\mathrm{x}}}$ is the concentration of oxygen vacancies $\left(1 / \mathrm{cm}^{3}\right) ; \mu_{v_{0}^{x}}$ is their mobility $\left(\mathrm{cm}^{2} / \mathrm{V} \mathrm{s}\right)$. The concentration of oxygen vacancies for $\mathrm{Ba}_{2-0.5 x}\left[\mathrm{~V}_{\mathrm{Ba}}\right]_{0.5 x} \mathrm{In}_{2} \mathrm{O}_{5-x} \mathrm{~F}_{x}\left[\mathrm{~V}_{\mathrm{o}}\right]_{1}$ solid solutions is unchanged; in the case of $\mathrm{Ba}_{2} \mathrm{In}_{2} \mathrm{O}_{5-0.5 y} \mathrm{~F}_{y}\left[\mathrm{~V}_{\mathrm{o}}\right]_{1-0.5 y}$, it decreases at an increase in the dopant concentration and is determined as $(1-0.5 y)$.

Figure 5 shows concentration dependences of mobility of oxygen vacancies at $700^{\circ} \mathrm{C}$ for solid solutions of $\mathrm{Ba}_{2-0.5 x} \operatorname{In}_{2} \mathrm{O}_{5-x} \mathrm{~F}_{x}$ and $\mathrm{Ba}_{2} \operatorname{In}_{2} \mathrm{O}_{5-0.5 y} \mathrm{~F}_{y}$. One can see that the highest oxygen mobility is observed for compositions with low fluoride additives $(x=0.10$ and $y=$ $0.02)$. Herewith, the maximums in the mobility curves 
$\log \sigma\left[\mathrm{S} \mathrm{cm}^{-1}\right]$

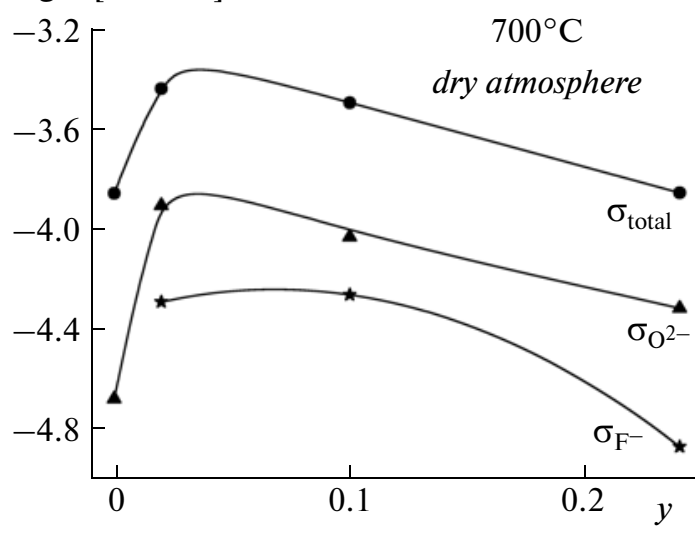

$\log \sigma\left[\mathrm{S} \mathrm{cm}^{-1}\right]$

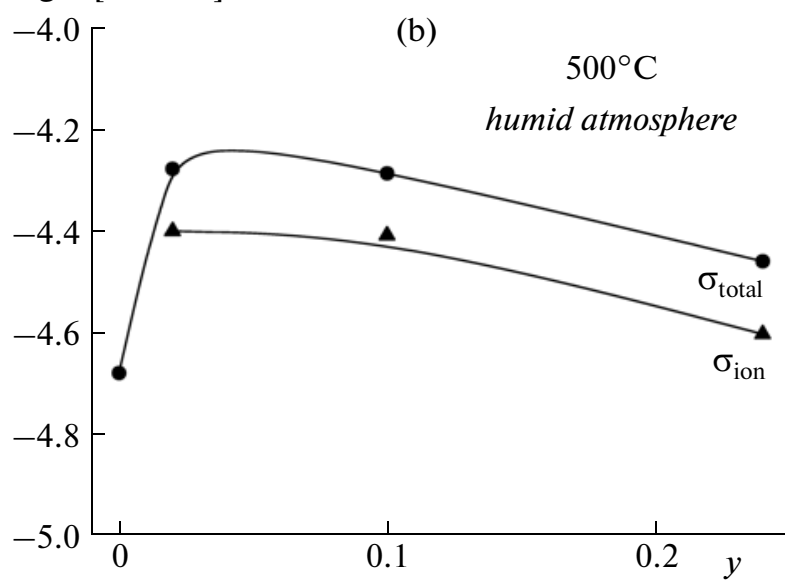

Fig. 4. Concentration dependences of total and partial conductivity for solid solutions of $\mathrm{Ba}_{2} \mathrm{In}_{2} \mathrm{O}_{5}-0.5 y \mathrm{~F}_{y}$ in (a) a dry atmosphere at $700^{\circ} \mathrm{C}$ and (b) a humid atmosphere at $500^{\circ} \mathrm{C}$.

coincide with the maximums observed in concentration dependences of ionic conductivity (Figs. 3, 4). In other words, low fluoride concentrations result in an increase in mobility of oxygen vacancies and therefore in an increase in the values of oxygen-ion conductivity.

Analysis of factors affecting mobility of ions allows stating that the geometric (size) factor is not the determinant when fluoride ions are introduced into the oxygen sublattice. As regards analysis of such bond characteristics as polarizability and change in its ionic character, one can assume that appearance of more ionic In-F bonds leads to an increase in the covalent character of the In-O bond. This is an unfavorable factor for an increase in oxygen mobility. Accordingly, this cause is also not determinant. In our opinion, it is more convincing to explain the change in mobility on the basis of electrostatic interaction between ions. Appearance in the same sublattice of two types of mobile anions must unavoidably result in additional effects of electrostatic repulsion, which actually results in an increase in mobility. This cause is probably most $\log \mu_{\mathrm{V}_{0}}\left[\mathrm{~cm}^{2} /(\mathrm{V} \mathrm{s})\right]$

(a)

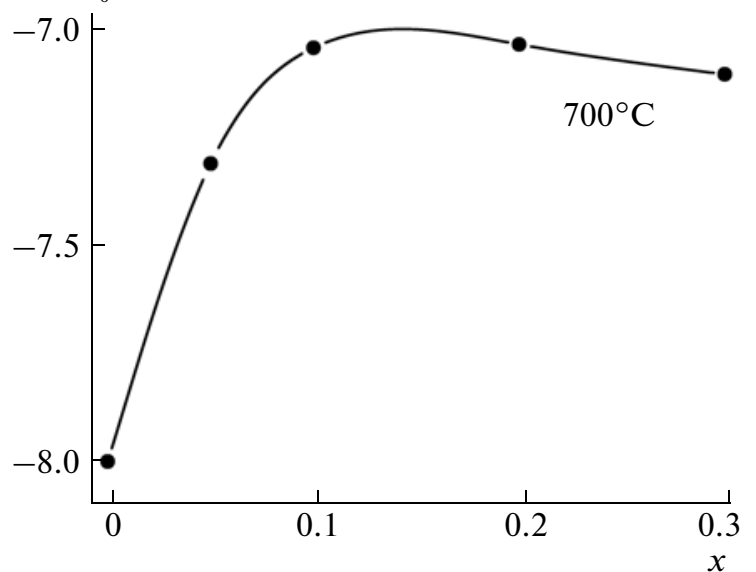

$\log \mu_{\mathrm{V}_{0}}\left[\mathrm{~cm}^{2} /(\mathrm{V} \mathrm{s})\right]$

(b)

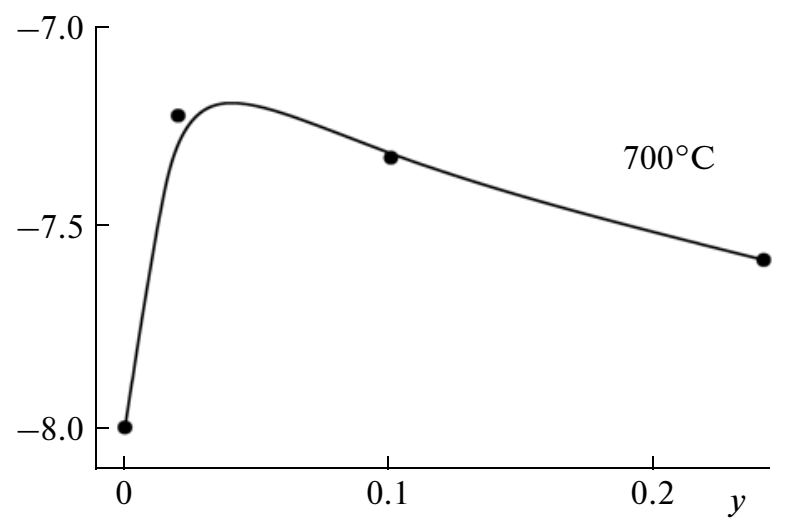

Fig. 5. Concentration dependence of mobilities of oxygen vacancies at $700^{\circ} \mathrm{C}$ for solid solutions of (a) $\mathrm{Ba}_{2-0.5 x} \mathrm{In}_{2} \mathrm{O}_{5-x} \mathrm{~F}_{x}$ and (b) $\mathrm{Ba}_{2} \mathrm{In}_{2} \mathrm{O}_{5-0.5 y} \mathrm{~F}_{y}$.

general and this circumstance allows considering this method, introduction of the second mobile anion, as the general method of increasing oxygen mobility on complex oxides with a perovskite-like structure.

These regularities are correct for the region of low fluoride concentrations, where $\mathrm{F}^{-}$ions are not the predominant carrier type, but still they activate the oxygen sublattice. The effects of a decrease in the oxygen mobility are obviously unavoidable in the region of significant fluoride concentrations. As transport of fluoride ions and oxygen ions occurs via the same defects, oxygen vacancies, diffusion-migration paths overlap and therefore the mobility decreases.

Dissociative dissolution of water vapors in the complex oxide matrix occurs in a humid atmosphere according to the quasichemical equation of

$$
\mathrm{H}_{2} \mathrm{O}+\mathrm{O}_{\mathrm{O}}^{\mathrm{x}}+\mathrm{V}_{\mathrm{O}}^{\mathrm{x}} \Leftrightarrow \mathrm{OH}_{\mathrm{O}}^{\cdot}+\mathrm{OH}_{\mathrm{V}_{\mathrm{o}}}^{\prime} \text {. }
$$

Localization of protons on oxygen in a regular position results in appearance of the defect of $\mathrm{OH}_{\mathrm{O}}^{-}$ and localization on oxygen from a water molecule 

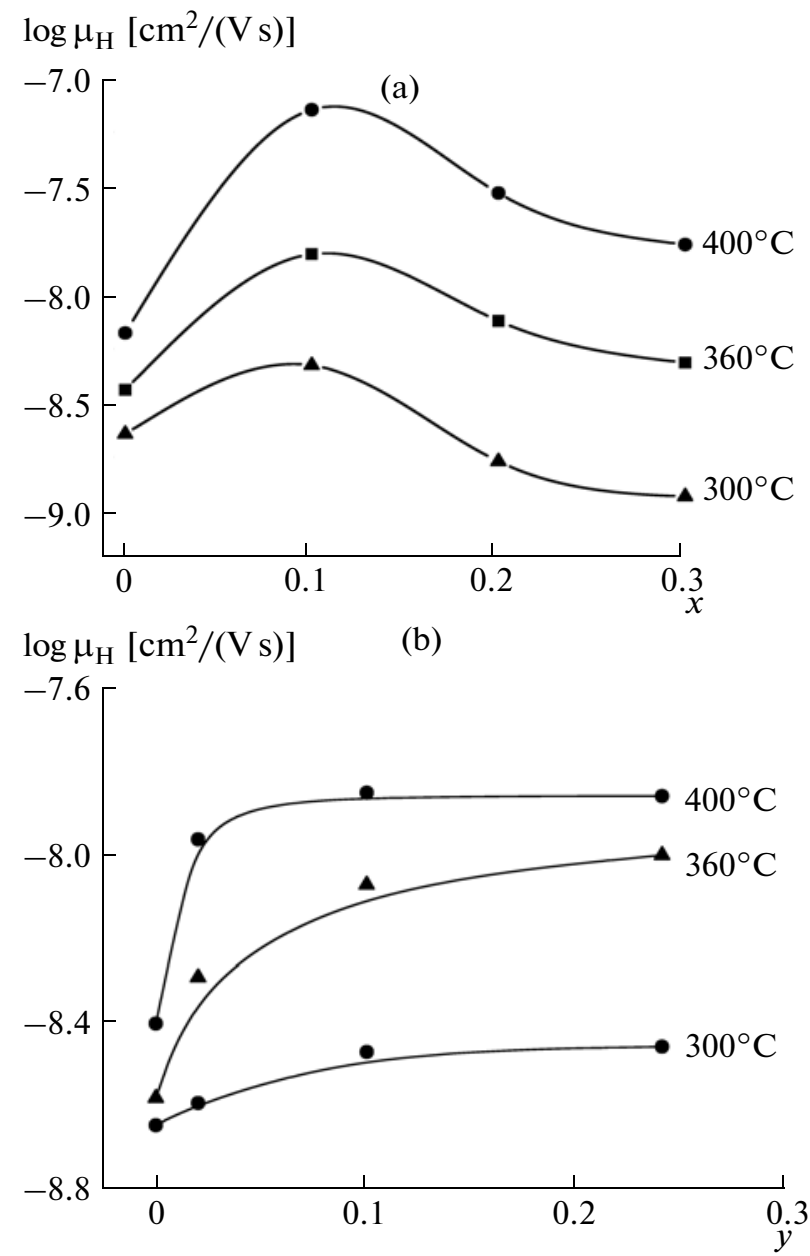

Fig. 6. Concentration dependences of mobilities of protons for solid solutions of (a) $\mathrm{Ba}_{2}-0.5 x \mathrm{In}_{2} \mathrm{O}_{5}{ }_{x} \mathrm{~F}_{x}$ and (b) $\mathrm{Ba}_{2} \mathrm{In}_{2} \mathrm{O}_{5-0.5 y} \mathrm{~F}_{y}$.

occupying a structural vacancy leads to appearance of $\mathrm{OH}_{\mathrm{V}_{\mathrm{o}}}^{\prime}$. The regularities of quasichemical description of water vapor dissolution processes for complex oxides containing structural vacancies of oxygen have been earlier discussed in most detail in [25, 26].

Mobility of proton carriers was calculated on the basis of the following equation:

$$
\sigma_{\mathrm{H}^{+}}=Z e c_{\mathrm{H}^{+}} \mu_{\mathrm{H}^{+}},
$$

where $c_{\mathrm{H}^{+}}$is the concentration of proton carriers, $\mu_{\mathrm{H}^{+}}$ is their mobility. The concentration of protons $\left(c_{\mathrm{H}^{+}}\right)$is calculated according to the equation:

$$
c_{\mathrm{H}^{+}}=\frac{n_{\mathrm{H}_{2} \mathrm{O}} 2}{V_{\text {cell }}},
$$

where $n_{\mathrm{H}_{2} \mathrm{O}}$ is the amount of absorbed water per lattice cell (calculation was based on the data of thermogravimetry of hydrated samples), $V_{\text {cell }}$ is the lattice cell volume.
Figure 6 shows concentration dependences of mobilities of protons for solid solutions of $\mathrm{Ba}_{2-0.5 x} \mathrm{In}_{2} \mathrm{O}_{5-x} \mathrm{~F}_{x}$ and $\mathrm{Ba}_{2} \mathrm{In}_{2} \mathrm{O}_{5-0.5 y} \mathrm{~F}_{y}$. One can see that addition of small concentrations of fluoride leads to an increase in mobility of proton carriers, which agrees well with the data on total conductivity in a humid atmosphere. This fact is obviously due to an increase in oxygen mobility in the presence of small concentrations of fluoride. It is well known at present that the dynamics of the oxygen sublattice determines mobility of protons. Indeed, correlation is observed in the concentration dependences of mobility of protons and of oxygen vacancies. In the region of high fluoride concentrations, mobility of protons decreases $\left(\mathrm{Ba}_{2}-0.5 x \mathrm{In}_{2} \mathrm{O}_{5-x} \mathrm{~F}_{x}\right)$ or changes negligibly $\left(\mathrm{Ba}_{2} \mathrm{In}_{2} \mathrm{O}_{5-0.5 y} \mathrm{~F}_{y}\right)$.

Thus, introduction of small concentrations of dopants with a higher mobility than that of the anions in the initial matrix results in activation of the oxygen sublattice and an increase in the mobility of ionic charge carriers both in dry and humid atmospheres, which accordingly, causes an increase in conductivity.

\section{ACKNOWLEDGMENTS}

The work was financially supported by the Russian Foundation for Basic Research (project no. 12-0331234 mol_a) and Ural Federal University development program with the financial support of young scientists.

\section{REFERENCES}

1. Reijers, R. and Haije, W., Literature Review on High Temperature Proton Conducting Materials. Energy Research Centre of the Netherlands, 2008. ECN-E-08-091.

2. Yao, T., Uchimoto, Y., Kinuhata, M., Inagaki, T., and Yoshida, H., Solid State Ionics, 2000, vol. 132, p. 189.

3. Yamamura, H., Yamada, Y., Toshiyuki, M., and Tooru, A., Solid State Ionics, 1998, vol. 108, p. 377.

4. Hashimoto, T., Yoshinaga, M., Ueda, Y., Komazaki, K., Asaoka, K., and Wang, S., J. Therm. Anal. Calorim., 2002, vol. 169, p. 909.

5. Ta, T.Q., Tsuji, T., and Yamamura, Y., J. Alloys Compd., 2006, vol. 408-412, p. 253.

6. Noirault, S., Quarez, E., Piffard, Y., and Joubert, O., Solid State Ionics, 2009, vol. 180, p. 1157.

7. Kakinuma, K., Yamamura, H., Haneda, H., and Atake, T., Solid State Ionics, 2001, vol. 140, p. 301.

8. Mitome, M., Okamoto, M., and Bando, Y., J. Vac. Sci. Technol., B: Microelectron. Nanometer Struct.-Process., Meas., Phenom., 2001, vol. 19, p. 2284.

9. Uchimoto, Y., Takagi, H., Yao, T., Ozawa, N., Inagaki, T., and Yoshida, H., J. Synchrotron Rad., 2001, vol. 8, p. 857.

10. Liu, Y., Withers, R.L., and Gerald, J.F., J. Solid State Chem., 2003, vol. 170, p. 247.

11. Kakinuma, K., Yamamura, H., Haneda, H., and Atake, T., Solid State Ionics, 2002, vol. 154-155, p. 571.

12. Kakinuma, K., Yamamura, H., and Atake, T., J. Therm. Anal. Calorim., 2002, vol. 69, p. 897. 
13. Schober, T., Solid State Ionics, 1998, vol. 109, p. 1.

14. Hideshima, N. and Hashizume, K., Solid State Ionics, 2010, vol. 181, p. 1659.

15. Quarez, E., Noirault, S., Caldes, T., and Joubert, O., J. Power Sources, 2010, vol. 195, p. 1136.

16. Jayaraman, V., Magrez, A., Caldes, M., Joubert, O., Ganne, M., Piffard, Y., and Brohan, L., Solid State Ionics, 2004, vol. 170, p. 17.

17. Jayaraman, V., Magrez, A., Caldes, M., Joubert, O., Taulelle, F., Rodriguez-Carvajal, J., Piffard, Y., and Brohan, L., Solid State Ionics, 2004, vol. 170, p. 25.

18. Rolle, A., Vannier, R.N., Giridharan, N.V., and Abraham, F., Solid State Ionics, 2005, vol. 176, p. 2095.

19. Rolle, A., Roussel, P., Giridharan, N.V., Suard, E., and Vannier, R.N., Solid State Ionics, 2008, vol. 179, p. 1986.
20. Rolle, A., Fafilek, G., and Vannier, R.N., Solid State Ionics, 2008, vol. 179, p. 113.

21. Tarasova, N.A. and Spesivtseva, I.V., Al'tern. Energ. Ekol., 2010, no. 8, p. 98.

22. Animitsa, I., Tarasova, N., and Filinkova, Ya., Solid State Ionics, 2012, vol. 207, p. 29.

23. Tarasova, N.A., Filinkova, Ya.V., and Animitsa, I.E., Russ. J. Phys. Chem. A, 2012, vol. 86, p. 1208.

24. Tarasova, N.A., Filinkova, Ya.V., and Animitsa, I.E., Russ. J. Electrochem., 2013, vol. 49, p. 50.

25. Animitsa, I.E., Neiman, A.Y., Sharafutdinov, A.R., and Kazakova, M.G., Russ. J. Electrochem., 2001, vol. 37, p. 266.

26. Animitsa, I., Norby, T., Marion, S., Glockner, R., and Neiman, A., Solid State Ionics, 2001, vol. 145, p. 357.

Translated by M. Ehrenburg 